summarizes our current knowledge of structure and function in addition to treating other special topics, such as regulation or comparison with other relevant molecules.

Although the book is clearly organized and provides a coherent treatment of the subject, one need not read it straight through. The two parts can, depending on the level of sophistication the reader brings to the material, be read independently and out of order, and each of the chapters treating a specific pump constitutes a brief, free-standing review of that pump.

\section{From know-how to nowhere}

\author{
Henry Petroski
}

Flying Buttresses, Entropy, and 0 Rings: The World of an Engineer. By James L. Adams. Harvard University Press: 1992. Pp. 264. \$24.95, £19.95 (hbk); £10.95 (pbk, UK and Europe only).

THIS book is a wide-ranging discussion of engineering from one engineer's perspective. It is intended primarily for general readers, for lay people who interact in their job or life with engineers, and for those thinking about studying engineering or seeking to add a technological component to their liberal education. Adams explains in his introduction that, as an engineer, he has been "often embarrassed by the relatively small number of readable general books on engineering, as opposed to the large number on the physical sciences and mathematics", and it is, in part, this paucity that led him to write his book.

What makes a book on engineering or any other subject readable is, of course, a highly subjective matter, and the problem of objectivity is compounded for an engineer reading a book intended mainly for nonengineers. Adams anticipates this, and in his introduction speaks to the professional, acknowledging that no two engineers are likely to have the same viewpoint and perspective on the "complex and multifaceted activity" in which they are engaged. Indeed, Adams hopes that engineers who experience too much of a mismatch between his perspective and theirs will write their own books to "help address the biases" in his. With such an apologetic and selfconscious introduction, Adams virtually throws down the gauntlet before the reviewer

It is usually easy to nit-pick about what is wrong with a book in one's field, but that would serve little purpose here unless the points of disagreement were
This lucid summary of ion pumps will be widely appreciated by those in the transport field, and it provides a fitting memorial for one of the field's intellectual leaders and innovators.

Charles F. Stevens is in the Molecular Neurobiology Laboratory. The Salk Institute, 10010 North Torrey Pines Road, La Jolla, California 92037, USA.

- The second edition of lonic Channels of Excitable Membranes by Bertil Hille has also recently been published by Sinauer $W$. H. Freeman, price $\$ 46.95, £ 37.95$. For a review see Nature 314, 388; 1985

materially to change the impression of engineering that the nonspecialist will take from this book. Adams does an admirable job of setting engineering in a broad historical perspective, pointing out that modern technology has very ancient roots. He also paints a very fair picture of the complexity of the endeavour, and demonstrates the origins of engineering problems and the variety of modes in which engineers work to attack them. The centrality of design and invention is discussed, as are the roles of mathematics, science, and research and development in leading up to the moments of truth embodied in production, manufacturing, assembly, testing and use. The importance of economic factors in engineering is discussed, and the implications for technology and society of regulation and participatory democracy are explored. In short, Adams covers in 250 pages or so just about as much as can be expected of an endeavour that touches and is touched by just about every aspect of civilization and culture.
The general reader is thus likely to get a good idea of what engineering is and what engineers do. How readable the book is will no doubt depend on the receptivity of the reader and the extent to which the book succeeds in drawing more combative readers into its flow. In this regard, some of Adams's seeming asides may prove to be obstacles. For example, in discussing the use of the computer to solve differential equations formerly solved by hand, Adams tells us that this technological development has left engineers time for "more important kinds of thinking", but he does not say what kinds of thinking are more important for an engineer. In discussing what students should be expected to do in a design project, he describes the necessity of finding information and then rather glibly admits that the first thing he himself does when seeking information is to ask someone, because he likes people better than libraries. No matter how many caveats Adams has put in his introduction about this being his personal point of view, such a remark (and its implied advice to students) will all too easily reinforce the caricature of the engineer as anti-intellectual, not to mention raising the eyebrows of any humanists who might read the book.

Henry Petroski is in the Department of Civil and Environmental Engineering, Duke University, Durham, North Carolina 27706, USA.

Of related interest is the second edition of The Maze of Ingenuity: Ideas and ldealism in the Development of Technology by Arnold Pacey. The book now contains several new chapters. Published by MIT Press, price $\$ 25$. $£ 22.50$ (hbk), \$12.95, £11.75 (pbk).

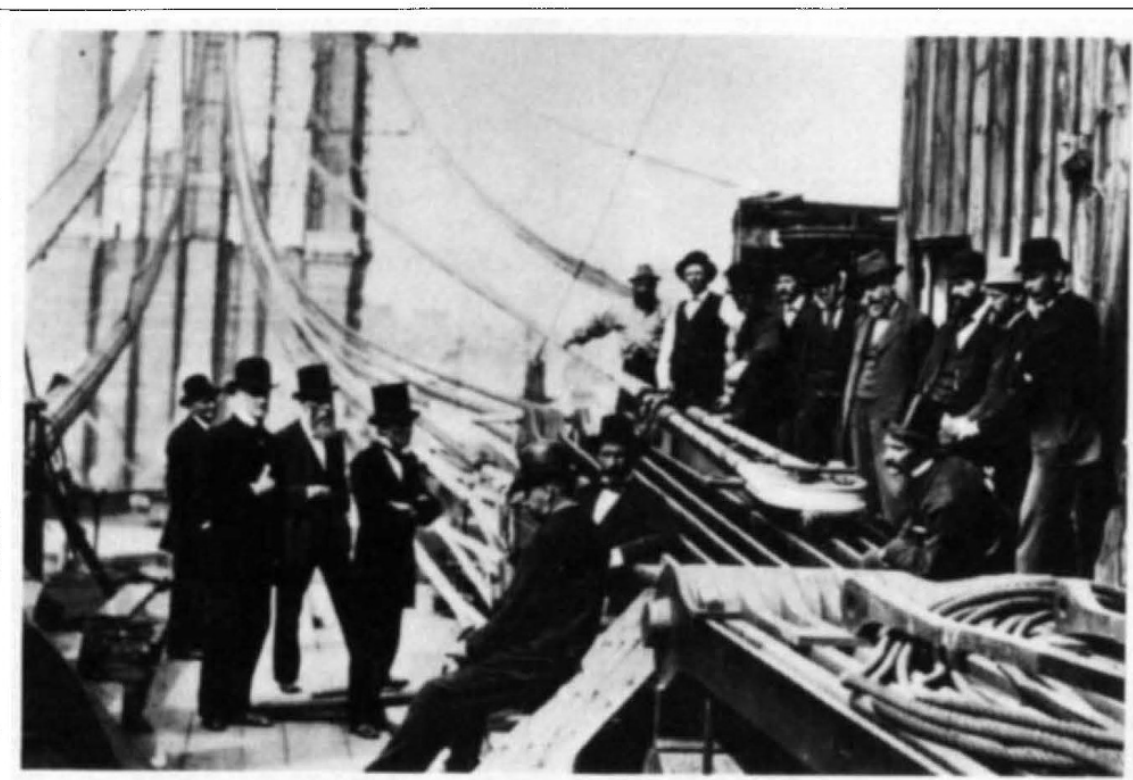

In suspense - Brooklyn Bridge under construction in 1878. Taken from The Engineer in America edited by Terry S. Reynolds, a historical anthology of essays originally published in the journal Technology and Culture. The book traces the rise of the profession over the past two centuries. Published by The University of Chicago Press, $\$ 44.95$ (hbk), \$19.95 (pbk). 